\title{
The role of EUS in diagnosis and treatment of liver disorders
}

\section{(ㄷ)(1)}

\author{
Authors \\ Sara Campos ${ }^{1,2}$, Jan-Werner Poley², Lydi van Driel' ${ }^{2}$, Marco J. Bruno ${ }^{2}$ \\ Institutions \\ 1 Department of Gastroenterology, Hospital Garcia da \\ Orta, Portugal \\ 2 Department of Gastroenterology and Hepatology, \\ Erasmus MC, The Netherlands \\ submitted 4.10.2018 \\ accepted after revision 7.1.2019 \\ Bibliography \\ DOI https://doi.org/10.1055/a-0958-2183 | \\ Endoscopy International Open 2019; 07: E1262-E1275 \\ (c) Georg Thieme Verlag KG Stuttgart · New York \\ elSSN 2196-9736 \\ Corresponding author \\ Sara Campos, Department of Gastroenterology, Hospital \\ Garcia da Orta - Gastroenterology, Av. Torrado da Silva \\ Almada, 2805-267, Portugal \\ Fax: +351212957004 \\ sara.campos@hgo.min-saude.pt
}

\section{ABSTRACT}

Background and aim Transabdominal ultrasound (US), computed tomographic scanning (CT) and magnetic resonance imaging (MRI) are established diagnostic tools for liver diseases. Percutaneous transhepatic cholangiography is used to perform hepatic interventional procedures including biopsy, biliary drainage procedures, and radiofrequency ablation. Despite their widespread use, these techniques have limitations. Endoscopic ultrasound (EUS), a tool that has proven useful for evaluating the mediastinum, esophagus, stomach, pancreas, and biliary tract, has an expanding role in the field of hepatology complementing the traditional investigational modalities. This review aimed to assess the current scientific evidence regarding diagnostic and therapeutic applications of EUS for hepatic diseases.

\section{Introduction}

Transabdominal ultrasound (US), computed tomographic (CT) scanning and magnetic resonance imaging (MRI) are established diagnostic tools for liver diseases. In addition, percutaneous interventions, most commonly with US or CT-guidance, are often used to perform a wide range of liver and biliary interventional procedures, including: vascular interventions (as transjugular intrahepatic portosystemic shunt and transjugular liver biopsy), percutaneous interventions (such as liver biopsy, collections/abscess drainage and transhepatic biliary interventions, namely percutaneous transhepatic cholangiography and/ or biliary drainage) and interventional oncologic therapeutic procedures (such as transarterial tumor embolization [hepatic radioembolization] and tumor ablations using thermal ablation techniques [radiofrequency ablation]). Despite their widespread use, these techniques have limitations. Endoscopic ultrasound (EUS), a first-line investigation method for evaluation of the mediastinum, esophagus, stomach, pancreas, and biliary tract, has an expanding role in the field of hepatology complementing the traditional investigational modalities. We aimed to review the current scientific evidence regarding diagnostic and therapeutic applications of EUS for hepatic diseases.

\section{Search strategies and criteria}

A search was performed in Pubmed with the keywords (liver OR hepatic) and (EUS OR "endoscopic ultrasound") and (diagnosis OR diagnostic OR treatment OR therapeutic OR ablation OR intervention). Inclusion criteria were: case reports, series, clinical studies, studies in animal models and reviews regarding EUS applications in liver disorders, including portal hypertension. Reports about the use of EUS in extrahepatic bile duct, gallbladder, and other extrahepatic structures were excluded. NonEnglish language literature without an English translation was also excluded. On March 4, 2018, the search yielded 1095 articles, 201 of which were included in this review. 


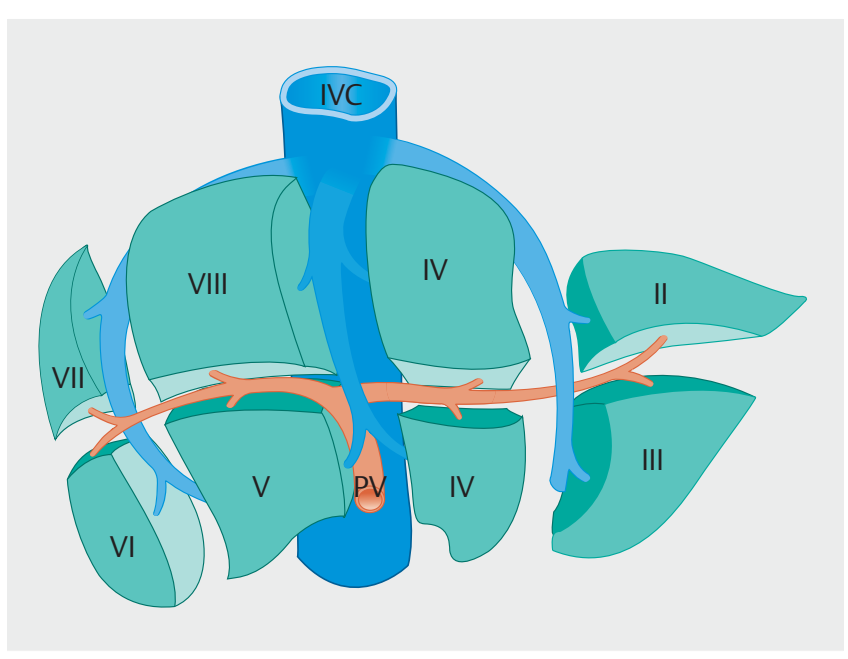

- Fig. 1 Liver segments described by Couinaud [1].

\section{Diagnostic role of EUS in liver disease}

Technical considerations

To evaluate the liver with EUS, one must first take into account that its perspective of liver anatomy is much different from US or CT images and requires three-dimensional conceptualization of the liver parenchyma. The Couinaud classification [1] is the most widely used system to describe liver anatomy and divides the liver into eight (I-VIII) functionally independent units, termed segments, based on planes through the hepatic veins $(\mathrm{HV})$ and the bifurcation of the main portal vein (PV) ( $\triangleright$ Fig. 1).

With EUS, these liver segments are recognized by identifying the following structures: (1) PV branches with thick and hyperechoic walls, Doppler positive; (2) HV branches (left and middle) with thin and non-reflective walls, straight course, Doppler positive; (3) biliary radicals with hyperechoic walls, irregular course, Doppler negative; (4) ligaments (venosum and teres) with thick and hyperechoic structures without lumen, extending between vessels and liver capsule; and (5) surface landmarks (gallbladder, falciform ligament and liver hilum). The longitudinal and cross-sectional schematic representations of linear EUS ( $>$ Fig. 2) through the liver from the proximal stomach with a clockwise probe rotation from A-D ( $>$ Fig. 2a) and from 1 - 4 ( $\triangleright$ Fig. 2b) must be taken into account.

A step-by-step endosonographic evaluation of the liver is performed as described by Bhatia et al. [2]. From the stomach, it is possible to evaluate the left lateral segments (segments II and III), as well as the umbilical part of the left PV and ligamentum teres (l.t.), the medial segment of the left lobe (segment IV), ligamentum venosum (I.v.), the caudate lobe (segment I), the inferior vena cava (IVC), the right lobe (segments $V$ and VIII) and the liver hilum. From the duodenal bulb, segments VI and VII, the hepatoduodenal ligament structures and PV and hepatic artery (HA) branches, the liver hilum and the segmental divisions of right $\mathrm{PV}$ and $\mathrm{HA}$ are visualized.

EUS has several potential advantages over other imaging modalities regarding optimal visualization of the liver: the EUS transducer can be positioned closely to the liver thereby avoiding interposing structures (such as rib cage, bowel loops, gall-

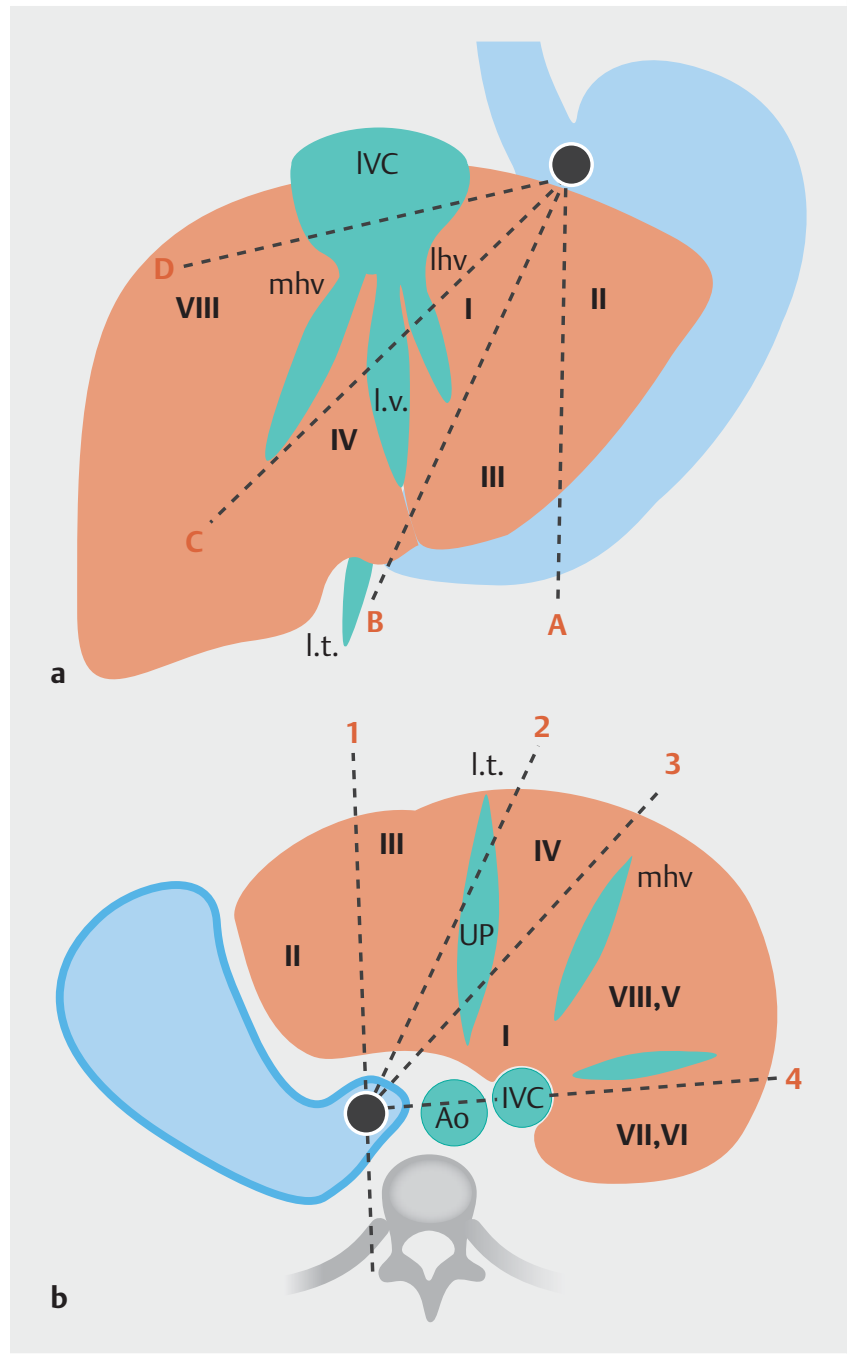

- Fig. 2 a Longitudinal and $\mathbf{b}$ cross-sectional schematic representations of linear EUS scans through the liver from the proximal stomach [2]. MHV, middle hepatic vein; LHV, left hepatic vein; UP, umbilical part of the left portal vein; Ao, aorta.

bladder, pleural space, ascites and a thickened abdominal wall, which are all well-known limitations of, for example, transabdominal ultrasound [3]), and it has the potential to thoroughly evaluate the left liver lobe, hilum and deeply-located areas of the liver, such as the caudate lobe. One potential limitation is the evaluation of the right lobe. It is examined from the duodenum, which is technically difficult because of the small endosonographic window and is possibly further compounded by the limited depth of penetration of the ultrasound waves [4].

Doppler ultrasound, through different implementations (as continuous-wave, pulsed-wave, color and power Doppler), can be used to identify blood flow in vessels. It is useful for characterizing liver anatomy, identifying interposed vessels during punctures and evaluating portal hypertension (PHT). Regarding vascular changes in PHT, EUS-Doppler has a distinct advantage over endoscopy, as it can reveal not only gastroesophageal varices, but also collaterals adjacent to or outside the wall such as periesophageal collateral veins (peri-ECV), paraesophageal col- 
lateral veins (para-ECV) collaterals and perforating veins [5-9]. Moreover, EUS can more accurately determine their size and wall thickness [10] and assess hemodynamic changes in portal and azygos veins and left gastric vessels, important parameters to consider for bleeding management.

Real-time elastography is another helpful tool that provides color-coded images and semi-quantitative measurements related to tissue stiffness of liver parenchyma and focal lesions as an additional tool in determining the etiology of the lesion. The need for manual tissue pressure required during standard transabdominal US elastography is overcome by comparing the ultrasound signals obtained over several seconds of normal breathing and blood circulation [11]. Also important is that elastography imaging via EUS is not limited by ascites and thickened abdominal wall [3].

Contrast-Enhancement (CE) is an emerging technique that is becoming more and more available to improve US and EUS diagnostic performance of focal liver lesions. CE-EUS is categorized into two types: CE-EUS with the Doppler method (CE-EUSD) and CE-EUS with harmonic imaging (CE-EUS-H). CE-EUS-D helps distinguishing between vascular-rich and hypovascular areas of a target lesion. CE-EUS-H provides a more detailed vasculature image of the target lesion. Both modes can be obtained to characterize a target lesion, and can be used depending on the purpose. Few US contrast agents are available worldwide, Sonovue and Sonazoid being the most widely used. These are made of microbubbles with a shell of phospholipids that are filled with sulfur hexafluoride gas. Since they are confined to the vessels after injection, it allows visualization of the tiny vessels in the capillary bed and therefore dynamic detection of capillary microvascularization. Given the dual blood supply of the liver, from the portal vein and the hepatic artery, three vascular phases can be observed with this ultrasound contrast: the arterial phase, beginning within 20 seconds after the injection and continuing for 30 to 45 seconds; the portal venous phase, that lasts up to 120 seconds; and then the late phase which persists until clearance of the US contrast agent from the circulation (usually 6 minutes). CE-EUS has several advantages over CT and MRI [12]: (1) It is performed in real time; (2) The contrast is not excreted by the kidneys, thus it does not need preinvestigational renal function testing and it can be used in patients with renal insufficiency, where contrast-enhanced CT or contrast-enhanced MRI are contraindicated; (3) Confinement in the vascular space without extravasation into the interstitial fluid allows a prolonged enhancement of the vascular system and the evaluation in the different vascular phases previously described; (4) It has a much higher resolution compared to other imaging modalities, enabling full study of the enhancement dynamics of lesions; and (5) It has an excellent tolerance and safety profile that makes it appropriate for repeated followup examinations.

EUS guided-liver biopsy (EUS-LB) may be safer than its percutaneous counterpart for performing hepatic tissue sampling in patients with coagulation disorders, such as those with liver cirrhosis $[13,14]$. The 19-gauge biopsy needle, which is smaller than the 16-gauge needles traditionally used in transcutaneous $\mathrm{LB}$, can be oriented under direct vision into the liver for sam- pling avoiding puncturing larger vessels [15]. Abdominal skin surgical scars, ascites or dense abdominal wall thickness are also not limitations. Few studies compared the yield of percutaneous versus EUS-guided liver sampling, concluding that specimen adequacy and diagnostic yield are at least comparable between both techniques, ranging from $90 \%$ to $100 \%$ [16]. Recently, a comparison between "blind" liver biopsies using different commercially available 19-gauge needles (Cook Echotip Procore, Olympus EZ Shot 2, Boston Scientific Expect Slimline, Covidien SharkCore) was performed and the Covidien Sharkcore needle produced statistically superior histological specimen by capturing more complete portal tracts, possible due to its design [17].

\section{Focal liver lesions}

EUS is a useful adjuvant to CT and MRI in diagnosing and characterizing focal liver lesions (FLL) [18, 19]. Several studies [4, $20-22$ ] have showed superiority of EUS over CT in detecting FLL, especially when they are small $(<1 \mathrm{~cm})$ or located in the left lobe or hilum. Awad et al. showed that EUS could diagnose additional hepatic lesions in $28 \%$ of patients with a history of known liver mass that were detected initially by CT [20].

Aside from detection, EUS may differentiate the etiology of these lesions using several tools.

First, a validated EUS scoring system has been developed, with a positive predictive value of $88 \%$ [23]. With this system, the presence or absence of certain criteria increases the accuracy to differentiate between malignant, benign or indeterminate FLL. Benign solid FLL are distinct hyperechoic and/or have a distinct geographic shape, while malignant lesions must have at least three of the following characteristics: two components (with isoechoic/slightly hyperechoic center or without isoechoic/slightly hyperechoic center), post-acoustic enhancement, adjacent structures distortion, hypoechogenicity (slightly or distinctly) and/or at least $10 \mathrm{~mm}$.

Second, EUS-elastography has been described in two studies $[24,25]$ as a valuable tool in detecting, characterizing and differentiating between benign and malignant FLL with sensitivity, specificity and diagnostic accuracy of $92.5 \%, 88.8 \%$ and $88.6 \%$, respectively. More high-quality data are needed to confirm the potential of EUS-elastography in this field.

Third, differentiation between different types of FLL can also be studied through vascular enhancement patterns with CEEUS, as is also done with CE-US [26] ( Fig. 3). Typical enhancement patterns are arterial hyperenhancement with subsequent slow washout in late-phase contrast in hepatocellular carcinoma (HCC), arterial hyperenhancement with rim-like enhancement and subsequent rapid washout in metastatic liver cancer [27] ( Fig.4), peripheral nodular hyperenhancement, with centripetal progressive fill-in in hemangioma, and arterial hyperenhancement with progressive, centrifugal complete, early, spoke-wheel arteries, unenhanced central scar in focal nodular hyperplasia [28].

Moreover, CE-US recently has been considered a useful tool for evaluating the effects of treatment of HCC. It can dynamically observe tumor vessel perfusion with superior diagnostic performance for residual tumors after transarterial chemoem- 
bolization (TACE) compared to CE-CT (sensitivity and accuracy of detecting residual tumor with CE-US $95.6 \%$ and $96.2 \%$ versus CE-CT $76.2 \%$ and $77.7 \%$, respectively) [29]. For this particular indication, CE-EUS could be of value, with the advantage of better examining the deeper liver lesions not visualized with CE-US [30]. However, this needs further confirmation.

In addition to the tools described above, EUS-guided tissue sampling can confirm a HCC diagnosis and avoid unnecessary surgery [22,31 - 48] (> Fig. 5).

Currently, EUS-guided sampling is indicated "if the pathological result is likely to affect patient management and the lesion is poorly accessible/not detected at percutaneous imaging or a sample obtained via the percutaneous route repeatedly yielded an inconclusive result" [15]. If cytohistopathological results are inconclusive, KRAS mutation can be analyzed as it provides high diagnostic yield in EUS-guided histopathological evaluation [49]. To reduce the number of needle passes and potential adverse events (AEs), novel ancillary techniques are being developed. A recent study [50] conducted in animal models demonstrated technical feasibility of in vivo cytological observation using a high-resolution microendoscopy (HRME) system under EUS guidance. The authors concluded that HRME could obtain clear images representing cytology-level morphology of liver and would therefore improve diagnostic accuracy of EUS-FNA for liver lesions. EUS-FNA may also play a significant role in staging $\mathrm{HCC}$ in patients with cirrhosis with PV thrombus by differentiating a tumor thrombus from a clot, as its etiology is difficult to assess in the absence of characteristic hallmarks [51-55]. This is of paramount importance in HCC management, as patients with tumor invasion into the PV are deemed to have unresectable disease and to be ineligible for transplant [56]. EUS-FNA of splenic vein thrombus has also been performed to clarify its etiology (benign versus malignant) [57]. A systematic review concerning complications related to EUSguided sampling showed a $2.33 \%$ rate of morbidity (bleeding, infection, pain, fever) and $0.29 \%$ rate of mortality (due to uncontrollable cholangitis) after 344 EUS-FNA of hepatic lesions [58]. Due to the long path required to reach the liver capsule and the fact that HCC is more vascular in comparison with other cancers (for example, pancreatic), one could presume a higher risk of tumor spillage into the peritoneal cavity along the needle track. Nonetheless, no such cases have been reported so far.

Lastly, convex EUS-Doppler can provide staging information regarding vascular invasion at the hepatic hilum, an important parameter to evaluate in, for example, peri-hilar cholangiocarcinomas [59].

\section{Liver cirrhosis}

Detection of liver fibrosis has important management and prognostic implications. Traditionally, liver biopsy is considered the "gold standard" diagnostic method for identifying liver cirrhosis, but has drawbacks regarding sampling errors, inter-observer variability and complications [60]. Noninvasive fibrosis markers, such as liver stiffness measurements (transient elastography - Fibroscan - and real-time elastography), have been developed to overcome these problems. Nonetheless, applicability of these measurements with a transabdominal approach is

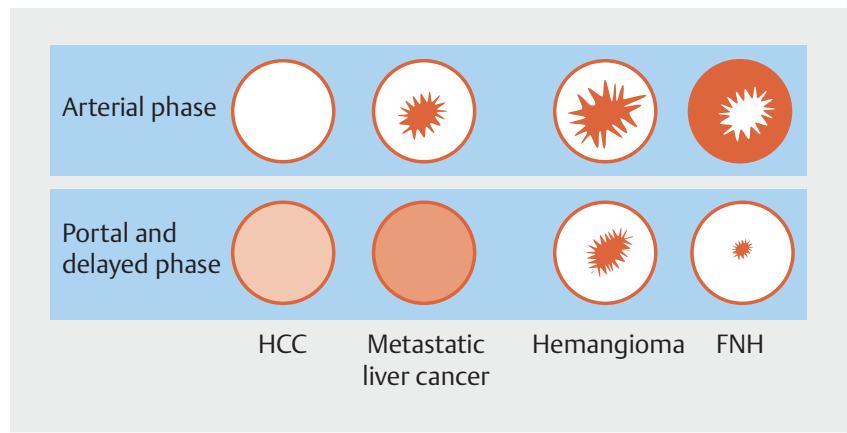

- Fig. 3 Typical enhancement patterns of FLL with contrast-enhanced ultrasound.

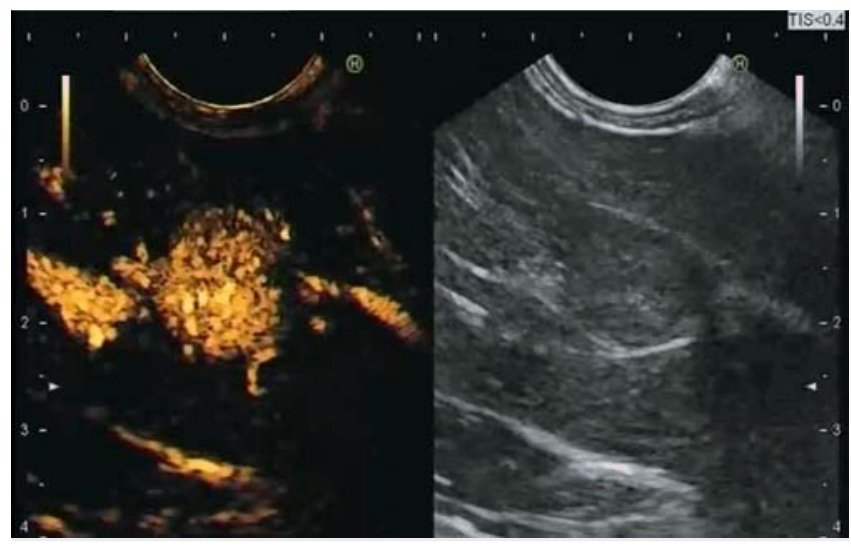

- Fig. 4 CE-EUS in liver metastases, with arterial hyperenhancement with rim-like enhancement.

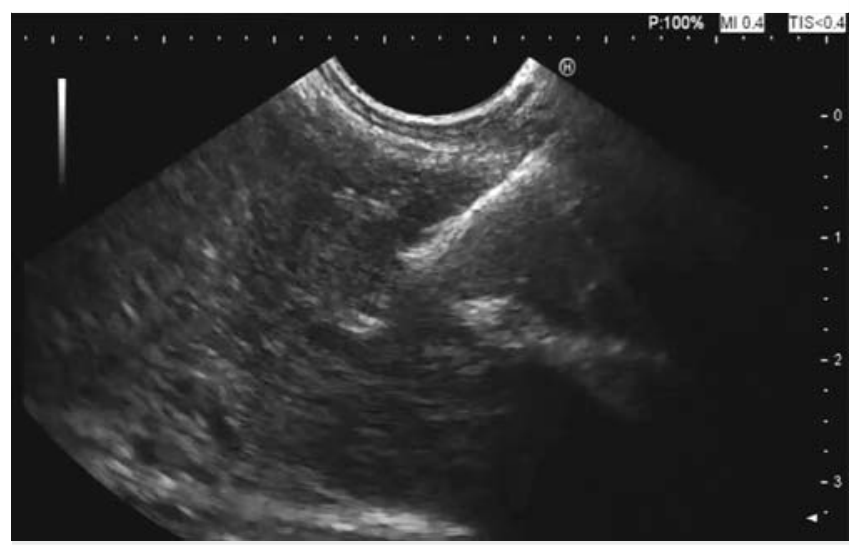

- Fig. 5 EUS-guided tissue sampling of a hepatic malignant lesion.

lower in cases of obesity or ascites and in discriminating between intermediate stages of fibrosis [60]. In addition, realtime elastography, used in EUS, can be advantageous over transabdominal Fibroscan, as it can estimate liver stiffness in all patients (either obese or not) and has the potential to differentiate between fibrosis and steatosis, as liver steatosis has a distinct appearance on real-time sono-elastography images, with low mean hue histogram values [61]. Further studies are needed, however, to confirm these hypotheses. 

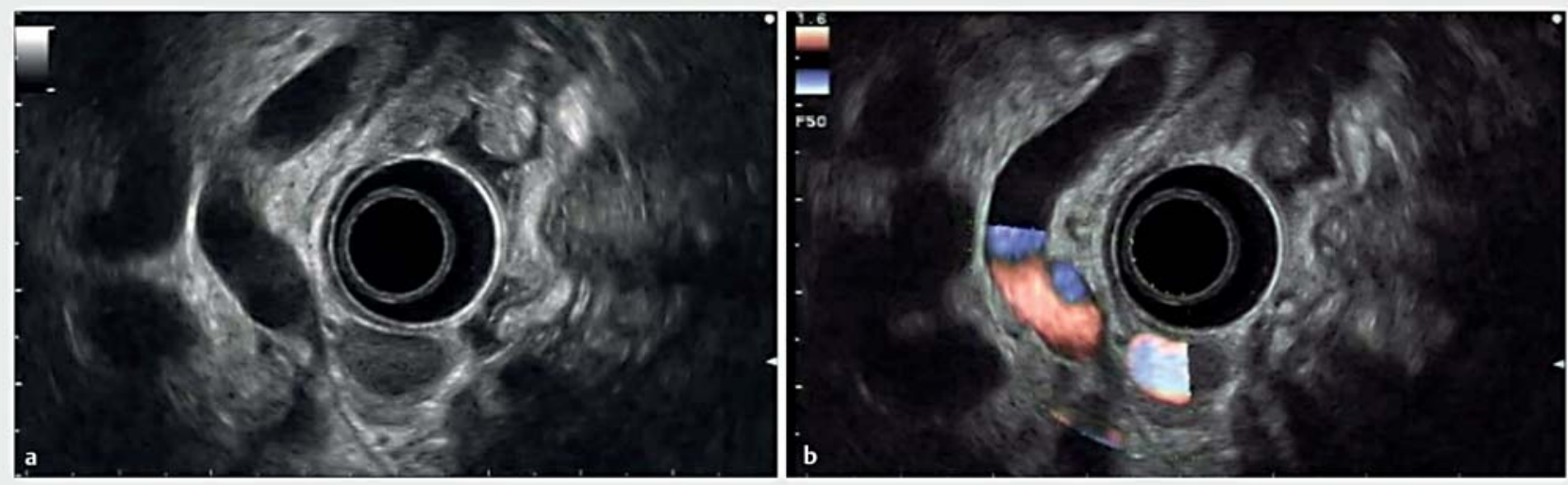

Fig. 6 Fundus varices in EUS a without Doppler and $\mathbf{b}$ with EUS-Doppler.

If histological confirmation is needed, EUS-guided LB is a safe technique with a diagnostic yield for liver parenchymal disorders such as liver cirrhosis, primary sclerosing cholangitis, autoimmune hepatitis and NAFLD between $91 \%$ and 100\% [6273], which is at least comparable to percutaneous or transjugular routes $[16,74,75]$. Few complications have been reported with this technique. Four self-limited pericapsular hematomas [72 - 74], two cases of duodenal perforations [23], one self-limited bleeding [62] and a case of a near-fatal hemorrhagic shock after EUS-LB [76] have been reported so far. Data on patient preference regarding being submitted to a percutaneous versus EUS liver biopsy are missing.

\section{Portal hypertension}

\section{Detecting vascular changes within and outside of the upper digestive wall}

EUS-Doppler has a higher sensitivity for detecting esophageal and gastric varices compared to upper endoscopy [5, 77-85] ( Fig.6).

It is also a useful modality for evaluating ectopic duodenal varices [86-90]. The higher the grade of esophageal varices, the higher the EUS sensitivity [82]. Success in visualizing small esophageal varices by EUS can be improved by using small water-filled balloons [77], small $20-\mathrm{Hz}$ ultrasound transducers $[91,92]$, videotaped high-resolution endoluminal sonography [81] or high-frequency ultrasound miniature probes [93].

EUS-doppler can diagnose collateral veins, which are found adjacent to or outside the esophageal wall in patients with esophageal varices [5-9]. There is a correlation between grade of esophageal varices and development and diameter of paraECV [5] and between diameter of the splenic vein and diameter of these collaterals [94].

EUS-Doppler can also substantiate diagnosis of portal gastropathy, showing diffuse thickening of the gastric wall with dilated paragastric veins $[6,95]$, thereby distinguishing it from watermelon stomach, which is characterized by focal swelling and spongy appearance in mucosa and submucosa [96, 97]. It is also valuable in differential diagnosis of giant gastric folds
[98, 99], distinguishing benign causes, such as gastric varices, from malignant causes.

\section{Dynamic assessment of hemodynamic changes}

The hepatic venous portal pressure gradient or portal pressure gradient (PPG) reflects the degree of PHT and is the single best prognostic indicator in liver disease. Currently, PPG measurement via right jugular vein access is considered the gold standard. Nonetheless, this is an indirect invasive measurement because it relies on a wedge pressure to assess portal vein pressure, and may not always accurately reproduce true PV pressures. EUS-guided PV catheterization was developed to overcome drawbacks of the transjugular approach. It was first performed in porcine models [100-105], appearing feasible and safe for portal pressure measurements as well as for portal angiography and pressure measurements. The first human clinical report was made by Fuji-Lau et al. [106]. Later, a human study $[106,107]$ involving 28 patients demonstrated a $100 \%$ technical success and no AEs in measuring the PPG with a linear echoendoscope, a 25G FNA-needle and a compact manometer. An excellent correlation was found between PPG measurement, clinical evidence of PHT, and clinical suspicion of liver cirrhosis. Larger clinical trials and comparative studies between both approaches are needed to confirm and establish the role of this technique.

\section{Prediction of variceal bleeding and rebleeding}

Elevated intravariceal pressure is associated with risk of variceal bleeding. In 1999, Jackson et al. developed a technique for directly measuring esophageal variceal wall tension using an ultrasonographic transducer and needle puncture of the varix [108]. Later, to avoid risk of variceal bleeding from needle puncture, Miller et al. [109, 110] developed a noninvasive EUSbased device by which they successfully measured intravariceal pressure in a varix model by placing a $20-\mathrm{MHz}$ ultrasound transducer in a latex balloon catheter sheath and attaching the catheter to a pressure transducer. Another indirect measurement of intravariceal pressure has been developed using EUS-Dopplerguided manometry of esophageal varices, using a linear EUS 
probe with power Doppler to assess flow in the varices and a manometry balloon attached to the tip of the probe [111]. Nonetheless, despite being promising, none of these methods are in widespread use today.

Other EUS predictors have also been found in relation to risk of variceal bleeding. Hematocystic spots on the surface of esophageal varices, identified in EUS as saccular aneurysms, are closely associated with high risk of variceal rupture [81, $112]$. By summing the cross-sectional surface area of all esophageal varices in the distal esophagus with digitized image, EUS can predict the risk of variceal bleeding: for each $1 \mathrm{~cm}^{2}$ increase in variceal cross-sectional surface area (CSA) the risk of variceal bleeding increases 76-fold per year [113]. Using a cutoff value for the CSA of $0.45 \mathrm{~cm}^{2}$, sensitivity and specificity for future variceal bleeding above and below this point are $83 \%$ and $75 \%$, respectively [113]. Furthermore, high blood flow variceal velocities and thin gastric variceal wall (mean thickness of the gastric wall of $1.2 \pm 0.2 \mathrm{~mm}$ ) correlate with greater bleeding risk [114]. Number and size of para and peri-ECV $[115,116]$ and perforating veins $[117,118]$ are also associated with risk of variceal bleeding.

EUS has a predictive value identifying rebleeding risk from esophageal varices by evaluating the type and grade of esophageal collaterals and cardiovascular structures [80, 119,120]. Collateral vessels in the vicinity of gastric cardia improve after endoscopic variceal ligation (EVL), indicating that esophageal varices can be treated by EVL even though they connect with cardia varices. Their disappearance is associated with longer periods free from recurrence of esophageal varices [121]. Patients with peri-ECV and perforator veins [77, 115, 122-124] and/or with large para-ECV $[83,116,125-128]$ are more likely to experience variceal recurrence and rebleeding. EUS can clearly predict recurrence of esophageal varices following $\mathrm{EVL}$ with a sensitivity and specificity of $89.2 \%$ and $90.5 \%$, respectively [124].

Paraesophageal diameter after EVL is a better recurrence predictor, because it has a lower cut-off parameter, higher sensitivity, and higher area under a ROC Curve (AUROC) $(4 \mathrm{~mm}$, $70.6 \%$ sensitivity, $84.6 \%$ specificity, 0.801 AUROC) [127]. A study using balloon-occluded retrograde transvenous obliteration for management of gastric varices concluded that presence of esophageal varices and high gastric variceal resistance index assessed by EUS $(\geq 0.24)$ before the procedure were significant risk factors for worsening of esophageal varices after obliteration [129]. Velocity of hepatofugal blood flow in the left gastric vein trunk can be determined, and also the branching pattern, both of which are associated with variceal recurrence after endoscopic treatments (anterior branch dominance and flow velocity of $12 \mathrm{c} / \mathrm{s}$ or more are associated with higher variceal recurrence) $[118,124,130,131]$.

\section{Assessment of pharmacological effects}

Variceal rupture results from increased variceal wall tension, which according to Laplace's law, is determined by transmural pressure difference, size and wall variceal thickness. Based on this formula, few studies have shown that EUS morphological assessment of varices (column radius and volume) combined with simultaneous pressure measurement are objective and useful tools for risk stratification $[132,133]$. The effects of somatostatin, octreotide, and terlipressin on azygos blood flow in patients with portal hypertension have also been well evaluated by EUS. EUS is capable of documenting a marked decrease of the azygos blood flow after injection of vasoactive agents, showing a potential role for monitoring pharmacological effects on the superior porto-systemic collateral circulation and portal venous flow in patients with portal hypertension [134-136].

In sum, there are several potential clinical applications of EUS in portal hypertension, namely in the evaluation of vascular changes of the digestive wall (through evaluation of esophageal and gastric varices, collateral veins and portal gastropathy), dynamic assessment of hemodynamic changes (through EUS-guided PV catheterization), prediction of variceal bleeding and rebleeding (through intravariceal pressure measurements, evaluation of hematocystic spots, summing the cross-sectional surface area of EV, calculation of type and grade of collateral veins) and assessment of pharmacological effects. Nonetheless, despite the multiplicity of possible uses, EUS currently does not have an established role in clinical practice to explore portal hypertension. More efficacy and safety data are needed.

\section{Therapeutic role of EUS}

\section{EUS-guided liver tumor ablation/injection}

Several EUS-guided liver tumor ablation/injection techniques have been described in the literature.

Radiofrequency ablation (RFA) is an alternative low-risk minimally invasive therapy for HCC and liver metastases when resection cannot be performed or, in case of HCC, when transplantation cannot be executed [137]. EUS-guided RFA with a prototype retractable umbrella-shaped electrode array has been created for effective coagulation necrosis of large areas, minimizing the risk of gastric mucosa damage [138]. More recently, a monopolar RFA under EUS guidance using a 1-Fr wire electrode (Habib) was introduced and tested in pig models $[139,140]$. Its flexible and thinner electrode could facilitate tissue access. Although one study did not show definite coagulative necrosis in the liver [139], another study did show positive results [140]. Further studies are needed to fully examine the response of tumor tissues to EUS-RFA.

Cryothermy (Cool-Tipped RFA) is a new flexible ablation device with a hybrid cryotherm probe that combines bipolar RFA with cryotechnology allowing for more efficient tissue ablation in the setting of lower temperatures provided by the cooling cryogenic gas [141]. In a single study, EUS-guided transgastric cryotherm ablation in porcine liver resulted in well-defined ablation areas without any complications [142].

Neodymium:yttium-aluminum-garnet (Nd-YAG) laser ablation is a minimally invasive method for solid tumor destruction by directing low-power laser light energy into tissue. Its advantages are use of thinner needles, shorter application time and the ability to reuse and re-sharpe the needle, which can be used at different angles. Di Matteo et al. [143] reported the first human case of EUS-guided Nd:YAG laser ablation for treat- 
ment of HCC located in the caudate lobe, with favorable prognosis. More recently, a prospective study including 10 patients with HCC or liver metastasis from colorectal carcinoma concluded that EUS-guided laser ablation might be technically feasible in selected tumors of the caudate lobe and left liver [144]. Nonetheless, the safety of this modality must be further confirmed in future studies.

High-intensity focused ultrasound (HIFU) was first developed as a thermal ablation method to ablate prostatic tissue and later to ablate liver metastases surgically or via a transcutaneous approach. Recently, a EUS-HIFU device has been created with the aim of treating tumors localized near the gastric lumen without the difficulties of gas interposition. Two reports, performed in living pig models, achieved complete necrosis of the lesions and had no immediate AEs $[145,146]$.

EUS-guided fine-needle ethanol injection was developed to deliver therapeutic agents to a target site more precisely and minimize damage to non-tumor tissue compared to the percutaneous approach. The efficacy and safety seen in the case reports and case series of EUS-guided ethanol injection in HCC [147-150] and hepatic metastasis [151,152] suggest a promising role for EUS in managing lesions that are difficult to access with conventional methods. After EUS-guided ethanol liver tumor injection, a self-limited subcapsular hematoma [152] was reported.

EUS-guided iodine-125 brachytherapy is another palliative treatment. Although usually performed percutaneously, EUSguided iodine-125 brachytherapy can be a safe and effective alternative for left-sided liver tumors refractory to transabdominal interventions [150].

EUS-guided portal injection chemotherapy (EPIC) using irinotecan-loaded microbeads in liver metastases can increase intrahepatic irinotecan concentrations while decreasing systemic exposure [153].

\section{EUS-guided fiducial placement for stereotactic body radiation therapy}

Use of EUS-guided fiducial placement for stereotactic body radiation therapy (SBRT) is becoming more widespread. Using multiple photon beams that intersect at a stereotactically determined target, it delivers higher doses of radiation into the tumor while sparing surrounding normal tissue. As the liver is very radiosensitive, accurate targeting of the tumor while salvaging normal hepatic parenchyma is crucial to prevent radiation-induced liver injury. SBRT requires implantation of fiducial markers in the lesion for adequate detection. EUS-guided fiducial placement seems to be a safe and technically feasible technique for preparing patients with deeper liver malignancies for SBRT that are not feasible for percutaneous approaches [154, 155].

\section{EUS-guided selective portal vein embolization}

Preoperative embolization of PV branches causing atrophy of the hepatic segments to be removed and subsequent compensatory hypertrophy of the remaining segments has proven to be safe and effective in patients undergoing extensive hepatectomy $[156,157]$. Matthes et al. [158] reported the first success- ful EUS-guided selective PV embolization with Enteryx (ethylene-vinyl alcohol copolymer) in a single swine model.

\section{EUS-guided cyst ablation}

Most simple liver cysts require no treatment. However, when they become symptomatic, treatment is indicated. Surgery is the classical approach, but as it leads to considerable morbidity rates, other less-invasive modalities were developed. Percutaneous aspiration (US or CT-guided) with lavage therapy with a sclerosing agent has demonstrated encouraging results with minimal AEs. More recently, EUS-guided aspiration and lavage therapy with alcohol has been postulated as having the advantage of not requiring insertion of a percutaneous drainage catheter, thus enabling alcohol lavage to be done with a onestep approach and has been considered a preferred approach to left lobe cysts [159]. There is a newer sclerosing agent used in EUS-FNA (1\% lauromacrogol) that seems to have fewer side effects than traditional ethanol and can thus be used as a replacement [160].

\section{EUS-guided liver abscess drainage}

Percutaneous drainage (PCD) is a first-line method for liver abscess drainage because of its minimal invasiveness and high technical success rate $[161,162]$. However, it has several disadvantages, such as external-drainage and self-tube removal that may lead to patient discomfort. Recently, EUS-guided liver abscess drainage (EUS-AD) has been developed with the advantages of doing one-step internal drainage (which has an obvious cosmetic benefit and avoids risk of self-tube removal and peritonitis). Nonetheless, only a few cases have been reported [163 - 173]. Even fewer reports can be found on EUS-AD using fully-covered self-expandable metallic stents (fcSEMS) [168172,174]. SEMS are expandable and have a larger diameter compared to plastic stents, resulting in impaction between the stent and the surrounding drainage area or abscess wall, and thus potentially less leakage into the abdominal cavity. In addition, the larger diameter allows for a better drainage effect, obviating the need for multiple sessions to clean the abscess and a lesser procedure time. If, however, a direct endoscopic necrosectomy is indicated, it can be easily performed through the large-bore stent. Finally, SEMS can also be helpful in hemostasis when unexpected bleeding from the tract occurs during the procedure. Ogura et al. [172] concluded that EUS-AD with fcSEMS is a potential first-line treatment for liver abscesses, particularly in the left liver lobe, as it is associated with shorter hospital stay, higher clinical success and lower AE rates compared to PCD. So far, only one case report has described a successful EUS-AD of the right hepatic lobe with SEMS [175].

Infected hepatic cysts are much rarer and only a single case has reported an effective EUS-guided drainage [176]. Rare infected intracystic papillary hepatic adenocarcinomas have also been successfully approached by EUS [177].

\section{EUS-guided therapy for portal hypertension}

Apart from improving the diagnosis, EUS can also assist in the management of PHT. 

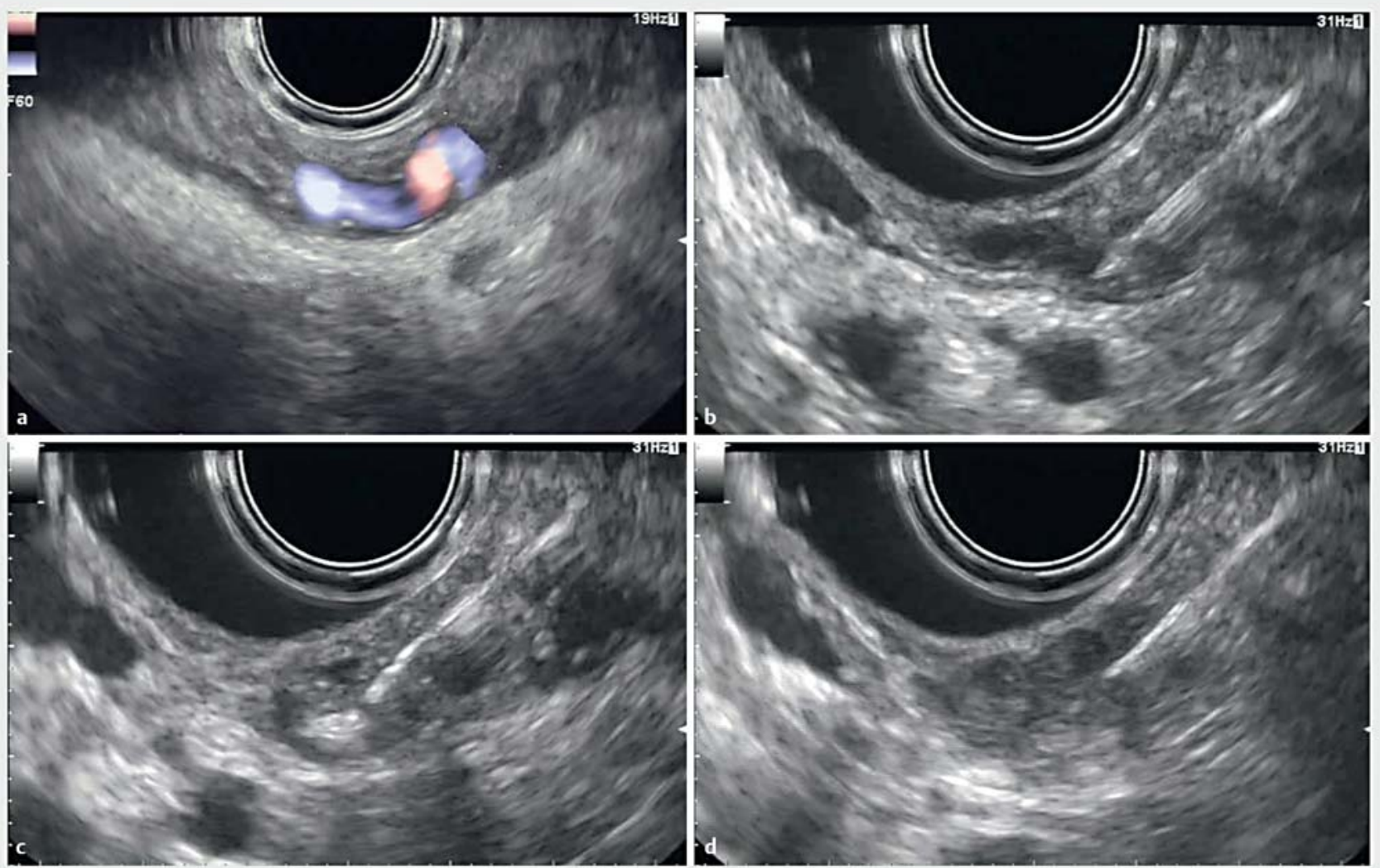

- Fig.7 EUS-guided cyanoacrylate in varices. a EUS-doppler evaluation of varices. b EUS-puncture of the varix. c EUS-guided cyanoacrylate. d Varix total obliteration with the cyanoacrylate.

Nagamine et al. [178] conducted a successful pilot study of a "modified" esophageal variceal ligation (EVL) technique using an EUS-color Doppler with the aim of decreasing variceal recurrence rate associated with traditional EVL. As it has been shown that persistence of patent varices, perforating veins or peri-ECV are associated with variceal recurrence, EVL performed with EUS can be advantageous compared to upper endoscopy as it can better identify these zones and assist in completing variceal eradication.

Esophageal varices can also be eradicated using EUS-guided sclerotherapy, as concluded in a randomized controlled study by Paulo et al. [179]. This procedure seems to reduce recurrence of esophageal varices after endoscopic therapy [180] and the azygus vein diameter [181]. Minor complications in EUS-sclerotherapy (as thoracic pain and self-limited bleeding) have been reported and do not seem to differ from the endoscopically induced complications [179].

For eradication of gastric varices, EUS-guided cyanoacrylate injection with/without coiling with precise injection in the collaterals veins can be valuable, both for obtaining hemostasis during active bleeding and in primary and secondary bleeding prophylaxis [182-191] (> Fig. 7).

EUS-guided cyanoacrylate injection with/without coiling has been also used for duodenal varices $[86,87,192]$. EUS can further be useful for evaluating adequacy of tissue adhesive in var- iceal obturation [193]. EUS-guided cyanoacrylate injection has been associated with fever, chest pain, post-injection ulcers, and asymptomatic pulmonary glue embolisms [182]. These AEs, however, seem to be fewer than with endoscopy-guided injection [186].

EUS-guided coiling is another option for embolization of gastric varices [194]. It requires fewer procedures and has fewer AEs than EUS-guided cyanoacrylate injection although larger comparative studies are needed [182]. One coil migration into the liver was described, but passed spontaneously retrograde into the portal vein and assumed a final position in the subcapsular liver without clinical sequelae [195] and few cases of selflimited bleeding have occurred at the puncture site during the procedure [196]. AEs associated with EUS-guided coil application tend to be fewer than with EUS-guided cyanoacrylate injection [182]. Combining cyanoacrylate injection and coil embolization showed favorable results in large studies [183, 197]. Combining both carries a $7 \% \mathrm{AE}$ rate (self-limited abdominal pain, pulmonary embolization, and bleeding) [187]. Good short-term outcomes after microcoil injection in anastomotic varices after total pancreatectomy have also been reported [196].

A case report of small bowel variceal bleeding demonstrated successful management using an EUS-assisted human thrombin injection [198]. 
Finally, traditional transjugular intrahepatic portosystemic shunt (TIPSS), an effective treatment for PHT complications, can be technically challenging when performed in the setting of IVC and HV obstruction. In addition, catheter manipulation through the right atrium and intrathoracic IVC may be dangerous in patients with severe cardiopulmonary disease. EUS-guided IPSS creation [103,199-201] was thus introduced as a potentially advantageous alternative as it does not require entrance into the heart or the IVC and decreases radiation exposure to both patient and physician during stent deployment. Also, it could become a valid therapeutic option in patients with active variceal bleeding that does not respond to endoscopic hemostasis and who are not stable enough to sustain transport to a radiology suite or when there is an anticipated delay before conventional TIPSS placement.

\section{Limitations of EUS}

The potential drawback of EUS when used for diagnostic purposes might be that it is invasive and expensive to perform. In addition, as already described, diagnostic accuracy is limited for lesions located in the right liver lobe or under the dome of the diaphragm. Presence of fatty infiltration, calcifications, pneumobilia, and extensive fibrosis may also interfere with ultrasound images. Altered anatomy (for example, presence of a pharyngeal diverticulum or a tight stricture), as is an upper gastrointestinal endoscopy, may also restrict EUS performance. Some of the EUS tools discussed here may also be unavailable. The endosonographer's experience and diligence by which the liver is scrutinized are of critical diagnostic and therapeutic importance.

Patients included in the studies either had no cirrhosis or a compensated cirrhosis. To fully evaluate use of EUS interventions, it would be very interesting to incorporate patients with decompensated cirrhosis in the study population, as they are susceptible to higher rates of complications such as bleeding/ infection.

A clear limitation of the current literature of EUS related to liver diseases is that the majority of the studies have been small, single-center, often retrospective and non-randomized. Experience with EUS interventional procedures in the liver remains limited mainly to animal feasibility studies and small human case series.

Therefore, although promising, much work needs to be done to firmly and scientifically establish the indication of diagnostic and therapeutic EUS in liver disease, including resolving issues pertaining its cost-effectiveness.

\section{Conclusion}

EUS has potentially significant clinical applications in diagnosis and treatment of liver disorders. It provides excellent, unobstructed, real-time imaging of the liver at high resolution. Adjunct tools such as Doppler, elastography, and contrast can be used to improve its diagnostic yield. EUS-guided interventional procedures to measure portal hepatic pressure, ablate hepatic tumors and cysts, and drain liver abscesses have great potential to be patient friendly, cost-effective treatment alternatives with limited risk of complications. It should also be recognized that EUS is limited in regard to right lobe access. All this potential calls for adequately designed, preferably randomized controlled studies to substantiate the promise of the technology and firmly establish the role of EUS in diagnostic and therapeutic algorithms for liver disorders.

\section{Competing interests}

None

\section{References}

[1] Couinaud C. [Liver lobes and segments: notes on the anatomical architecture and surgery of the liver ]. Presse Med 1954; 62: 709-712

[2] Bhatia V, Hijioka S, Hara K et al. Endoscopic ultrasound description of liver segmentation and anatomy: Endoscopic ultrasound anatomy of liver. Dig Endosc 2014; 26: 482 - 490

[3] Andanappa HK, Dai Q, Korimilli A et al. Acoustic liver biopsy using endoscopic ultrasound. Dig Dis Sci 2008; 53: 1078-1083

[4] Singh P, Mukhopadhyay P, Bhatt B et al. Endoscopic ultrasound versus CT scan for detection of the metastases to the liver: results of a prospective comparative study. J Clin Gastroenterol 2009; 43: 367 373

[5] Caletti G, Brocchi E, Baraldini M et al. Assessment of portal hypertension by endoscopic ultrasonography. Gastrointest Endosc 1990; 36: $S 21-S 27$

[6] Seicean A. Endoscopic ultrasound in the diagnosis and treatment of upper digestive bleeding: a useful tool. J Gastrointest Liver Dis JGLD 2013; 22: $465-469$

[7] Wiechowska-Kozłowska A, Zasada K, Milkiewicz M et al. Correlation between endosonographic and doppler ultrasound features of portal hypertension in patients with cirrhosis. Gastroenterol Res Pract 2012; 2012: $1-5$

[8] Wiechowska-Kozlowska A, Raszeja-Wyszomirska J, Wasilewicz MP et al. Upper gastrointestinal endosonography in patients evaluated for liver transplantation. Transplant Proc 2009; 41: 3082 - 3084

[9] Hsieh J-S, Wang W-M, Perng D-S et al. Modified devascularization surgery for isolated gastric varices assessed by endoscopic ultrasonography. Surg Endosc 2004; 18: 666-671

[10] Schiano TD, Adrain AL, Cassidy MJ et al. Use of high-resolution endoluminal sonography to measure the radius and wall thickness of esophageal varices. Gastrointest Endosc 1996; 44: 425-428

[11] Jacobson BC. Pressed for an answer: has elastography finally come to EUS? Gastrointest Endosc 2007; 66: $301-303$

[12] Claudon M, Dietrich C, Choi B et al. Guidelines and good clinical practice recommendations for contrast enhanced ultrasound (CEUS) in the liver - update 2012. Ultraschall Med - Eur J Ultrasound 2012; 34: $11-29$

[13] Hollerbach S, Reiser M, Topalidis T et al. Diagnosis of hepatocellular carcinoma (hcc) in a high-risk patient by using transgastric EUSguided fine-needle biopsy (EUS-FNA). Z Für Gastroenterol 2003; 41: 995- 998

[14] Choudhary N, Bansal R, Puri R et al. Impact and safety of endoscopic ultrasound guided fine needle aspiration on patients with cirrhosis and pyrexia of unknown origin in India. Endosc Int Open 2016; 04: E953-E956

[15] Dumonceau J-M, Deprez P, Jenssen C et al. Indications, results, and clinical impact of endoscopic ultrasound (EUS)-guided sampling in 
gastroenterology: European Society of Gastrointestinal Endoscopy (ESGE) Clinical Guideline - Updated January 2017. Endoscopy 2017; 49: $695-714$

[16] Pineda J], DiehI DL, Miao CL et al. EUS-guided liver biopsy provides diagnostic samples comparable with those via the percutaneous or transjugular route. Gastrointest Endosc 2016; 83: 360 - 365

[17] Lee WJ, Uradomo LT, Zhang Y et al. Comparison of the Diagnostic yield of EUS needles for liver biopsy: ex vivo study. Diagn Ther Endosc 2017; 2017: 1 - 5

[18] Prasad P, Schmulewitz N, Patel A et al. Detection of occult liver metastases during EUS for staging of malignancies. Gastrointest Endosc 2004; 59: $49-53$

[19] McGrath K, Brody D, Luketich J et al. Detection of unsuspected left hepatic lobe metastases during EUS staging of cancer of the esophagus and cardia. Am J Gastroenterol 2006; 101: 1742-1746

[20] Awad SS, Fagan S, Abudayyeh S et al. Preoperative evaluation of hepatic lesions for the staging of hepatocellular and metastatic liver carcinoma using endoscopic ultrasonography. Am J Surg 2002; 184 : 601-604; discussion 604-605

[21] Singh P, Erickson RA, Mukhopadhyay P et al. EUS for detection of the hepatocellular carcinoma: results of a prospective study. Gastrointest Endosc 2007; 66: 265-273

[22] Nguyen P, Feng JC, Chang KJ. Endoscopic ultrasound (EUS) and EUSguided fine-needle aspiration (FNA) of liver lesions. Gastrointest Endosc 1999; 50: $357-361$

[23] Fujii-Lau LL, Abu Dayyeh BK, Bruno M] et al. EUS-derived criteria for distinguishing benign from malignant metastatic solid hepatic masses. Gastrointest Endosc 2015; 81: 1188-1196.e7

[24] Nadan R, Irena H, Milorad O et al. EUS elastography in the diagnosis of focal liver lesions. Gastrointest Endosc 2007; 66: 823-824

[25] Sandulescu L, Padureanu V, Dumitrescu C et al. A pilot study of real time elastography in the differentiation of focal liver lesions. Curr Health Sci ] 2012; 38: $32-35$

[26] D’Onofrio M, Crosara S, De Robertis R et al. Contrast-Enhanced UItrasound of Focal Liver Lesions. Am J Roentgenol 2015; 205: W56W66

[27] Minaga K, Takenaka M, Kitano M et al. 115 Improved diagnosis of liver metastases using kupffer-phase image of contrast-enhanced harmonic endoscopic ultrasonography in patients with pancreatic cancer. Gastrointest Endosc 2017; 85: AB53

[28] Xu H-X. Contrast-enhanced ultrasound: The evolving applications. World J Radiol 2009; 1: 15

[29] Liu M, Lin M, Lu M et al. Comparison of contrast-enhanced ultrasound and contrast-enhanced computed tomography in evaluating the treatment response to transcatheter arterial chemoembolization of hepatocellular carcinoma using modified RECIST. Eur Radiol 2015; 25: $2502-2511$

[30] Nakaji S, Hirata N. Evaluation of the viability of hepatocellular carcinoma in the caudate lobe using contrast-enhanced endoscopic ultrasonography after transarterial chemoembolization. Endosc Ultrasound 2016; 5: 390

[31] DeWitt ]. Endoscopic ultrasound-guided fine needle aspiration cytology of solid liver lesions: a large single-center experience. Am J Gastroenterol 2003; 98: 1976-1981

[32] Crowe DR, Eloubeidi MA, Chhieng DC et al. Fine-needle aspiration biopsy of hepatic lesions: Computerized tomographic-guided versus endoscopic ultrasound-guided FNA. Cancer 2006; 108: 180-185

[33] Hollerbach S, Willert J, Topalidis T et al. Endoscopic ultrasoundguided fine-needle aspiration biopsy of liver lesions: histological and cytological assessment. Endoscopy 2003; 35: 743-749

[34] Anand D, Barroeta JE, Gupta PK et al. Endoscopic ultrasound guided fine needle aspiration of non-pancreatic lesions: an institutional experience. J Clin Pathol 2007; 60: 1254-1262
[35] Crowe A, Knight CS, Jhala D et al. Diagnosis of metastatic fibrolamellar hepatocellular carcinoma by endoscopic ultrasound guided fine needle aspiration. Cyto]ournal [Internet] 2011; 8: 2

[36] Kawakami H, Kuwatani M, Sakamoto N. Hepatobiliary alveolar echinococcosis infiltration of the hepatic hilum diagnosed by endoscopic ultrasonography-guided fine-needle aspiration. Dig Endosc 2013; 25: $339-340$

[37] Lee YN, Moon JH, Kim HK et al. Usefulness of endoscopic ultrasoundguided sampling using core biopsy needle as a percutaneous biopsy rescue for diagnosis of solid liver mass: Combined histological-cytological analysis: EUS-guided biopsy for solid liver mass. J Gastroenterol Hepatol 2015; 30: 1161 -1166

[38] Reyes MCD, Huang X, Bain A et al. Primary pancreatic leiomyosarcoma with metastasis to the liver diagnosed by endoscopic ultrasound-guided fine needle aspiration and fine needle biopsy: A case report and review of literature. Diagn Cytopathol 2016; 44: 1070 1073

[39] Peng HQ, Darwin P, Papadimitriou JC et al. Liver metastases of pancreatic acinar cell carcinoma with marked nuclear atypia and pleomorphism diagnosed by EUS FNA cytology: a case report with emphasis on FNA cytological findings. CytoJournal 2006; $3: 29$

[40] Schulman AR, Thompson CC, Odze R et al. Optimizing EUS-guided liver biopsy sampling: comprehensive assessment of needle types and tissue acquisition techniques. Gastrointest Endosc 2017; 85: $419-426$

[41] Lopes C, de Garcia R, Santos G et al. Gastric compression due to a cystic liver metastasis of vulvar carcinoma diagnosed by endoscopic ultrasound-guided fine-needle aspiration. Endoscopy 2014; 46: E208-E209

[42] Yang D, Zhu H, DiMaio C]. Abdominal Splenosis mimicking a liver mass: diagnosis by EUS-FNA. Clin Gastroenterol Hepatol 2016; 14: e16-e17

[43] Husney J, Guttmann S, Anyadike N et al. Endoscopic ultrasound-fine needle aspiration: A novel way to diagnose a solitary extramedullary plasmacytoma of the liver. Endosc Ultrasound 2016; 5: 134

[44] Oh D, Seo D-W, Hong S-M et al. Endoscopic ultrasound-guided fineneedle aspiration can target right liver mass. Endosc Ultrasound 2017; 6: 109

[45] tenBerge J, Hoffman BJ, Hawes RH et al. EUS-guided fine needle aspiration of the liver: Indications, yield, and safety based on an international survey of 167 cases. Gastrointest Endosc 2002; 55: 859 862

[46] Prachayakul V, Aswakul P, Kachintorn U. EUS guided fine needle aspiration cytology of liver nodules suspicious for malignancy: yields, complications and impact on management. J Med Assoc Thail Chotmaihet Thangphaet 2012; 95: S56-S60

[47] Bogstad J, Vilmann P, Burcharth F. Early detection of recurrent hepatocellular carcinoma by endosonographically guided fine-needle aspiration biopsy. Endoscopy 1997; 29: 322 - 324

[48] Goel RK, Jha B, Mohapatra I et al. A liver mass in a case of gastrointestinal stromal tumour of the stomach is not always a metastasis. Cytopathology 2016; 27: 74-76

[49] Choi HJ, Moon JH, Kim HK et al. KRAS mutation analysis by nextgeneration sequencing in endoscopic ultrasound-guided sampling for solid liver masses: KRAS mutation analysis in EUS sampling. J Gastroenterol Hepatol 2017; 32: 154 - 162

[50] Suzuki R, Shin D, Richards-Kortum R et al. In vivo cytological observation of liver and spleen by using high-resolution microendoscopy system under endoscopic ultrasound guidance: A preliminary study using a swine model. Endosc Ultrasound 2016; 5: 239

[51] Kayar Y, Turkdogan KA, Baysal B et al. EUS-guided FNA of a portal vein thrombus in hepatocellular carcinoma. Pan Afr Med J 2015; 21: 86 
[52] Lai R, Stephens V, Bardales R. Diagnosis and staging of hepatocellular carcinoma by EUS-FNA of a portal vein thrombus. Gastrointest Endosc 2004; 59: $574-577$

[53] Storch I, Gomez C, Contreras F et al. hepatocellular carcinoma (HCC) with portal vein invasion, masquerading as pancreatic mass, diagnosed by endoscopic ultrasound-guided fine needle aspiration (EUSFNA). Dig Dis Sci 2007; 52: 789-791

[54] Moreno M, Gimeno-García A, Corriente M et al. EUS-FNA of a portal vein thrombosis in a patient with a hidden hepatocellular carcinoma: confirmation technique after contrast-enhanced ultrasound. Endoscopy 2014; 46: E590-E591

[55] Michael H, Lenza C, Gupta M et al. Endoscopic ultrasound -guided fine-needle aspiration of a portal vein thrombus to aid in the diagnosis and staging of hepatocellular carcinoma. Gastroenterol Hepatol 2011; 7: $124-129$

[56] European Association For The Study Of The Liver. European Organisation For Research And Treatment Of Cancer. EASL-EORTC clinical practice guidelines: management of hepatocellular carcinoma. J Hepatol 2012; 56: 908 - 943

[57] Delconte G, Bhoori S, Milione M et al. Endoscopic ultrasound-guided fine needle aspiration of splenic vein thrombosis: a novel approach to the portal venous system. Endoscopy 2016; 48: E40 -E41

[58] Wang K-X, Ben Q-W, Jin Z-D et al. Assessment of morbidity and mortality associated with EUS-guided FNA: a systematic review. Gastrointest Endosc 2011; 73: 283-290

[59] Hara K, Bhatia V, Hijioka S et al. A convex EUS is useful to diagnose vascular invasion of cancer, especially hepatic hilus cancer: a convex EUS is useful to diagnose. Dig Endosc 2011; 23: 26- 28

[60] EASL-ALEH Clinical Practice Guidelines: Non-invasive tests for evaluation of liver disease severity and prognosis. J Hepatol 2015; 63: $237-264$

[61] Rimbaş M, Gheonea DI, Săndulescu L et al. EUS elastography in evaluating chronic liver disease. Why not from Inside? Curr Health Sci ] 2009; 35: 225-227

[62] Diehl D, Johal A, Khara $\mathrm{H}$ et al. Endoscopic ultrasound-guided liver biopsy: a multicenter experience. Endosc Int Open 2015; 3: E210E215

[63] Stavropoulos SN, Im GY, Jlayer Z et al. High yield of same-session EUS-guided liver biopsy by 19 -gauge FNA needle in patients undergoing EUS to exclude biliary obstruction. Gastrointest Endosc 2012; 75: $310-318$

[64] Lutz H, Wasmuth H, Streetz K et al. Endoscopic ultrasound as an early diagnostic tool for primary sclerosing cholangitis: a prospective pilot study. Endoscopy 2012; 44: 934 - 939

[65] DeWitt ], McGreevy K, Cummings O et al. Initial experience with EUS-guided Tru-cut biopsy of benign liver disease. Gastrointest Endosc 2009; 69: 535-542

[66] Mathew A. EUS-guided routine liver biopsy in selected patients. Am J Gastroenterol 2007; 102: 2354-2355

[67] Gleeson FC, Clayton AC, Zhang L et al. Adequacy of endoscopic ultrasound core needle biopsy specimen of nonmalignant hepatic parenchymal disease. Clin Gastroenterol Hepatol 2008; 6: 1437 1440

[68] Nakai Y, Samarasena J, Iwashita T et al. Autoimmune hepatitis diagnosed by endoscopic ultrasound-guided liver biopsy using a new 19-gauge histology needle. Endoscopy 2012; 44: E67 -E68

[69] Gor N, Salem SB, Jakate S et al. Histological adequacy of EUS-guided liver biopsy when using a 19-gauge non-Tru-Cut FNA needle. Gastrointest Endosc 2014; 79: 170-172

[70] Sey MSL, Al-Haddad M, Imperiale TF et al. EUS-guided liver biopsy for parenchymal disease: a comparison of diagnostic yield between two core biopsy needles. Gastrointest Endosc 2016; 83: 347-352
[71] Johal A, Khara H, Maksimak M et al. Endoscopic ultrasound-guided liver biopsy in pediatric patients. Endosc Ultrasound 2014; 3: 191

[72] Saab S, Phan J, Jimenez MA et al. Endoscopic ultrasound liver biopsies accurately predict the presence of fibrosis in patients with fatty liver. Clin Gastroenterol Hepatol 2017; 15: 1477-1478

[73] Shah ND, Sasatomi E, Baron TH. Endoscopic ultrasound-guided parenchymal liver biopsy: single center experience of a new dedicated core needle. Clin Gastroenterol Hepatol 2017; 15: 784 - 786

[74] Nieto J, Khaleel H, Challita Y et al. EUS-guided fine-needle core liver biopsy sampling using a novel 19 -gauge needle with modified 1-pass, 1 actuation wet suction technique. Gastrointest Endosc 2018; 87: 469-475

[75] Shahshahan M, Gertz H, Fakhreddine AY et al. Mo1285 endoscopic ultrasound-guided liver biopsy versus percutaneous and trans-jugular liver biopsy for evaluation of liver parenchyma. Gastrointest Endosc 2017; 85: AB490

[76] Hassan G, Sahai A, Paquin S. Near-fatal hemorrhagic shock after endoscopic ultrasound-guided liver biopsy. Endoscopy 2015; 47: E378-E388

[77] Choudhuri G, Dhiman RK, Agarwal DK. Endosonographic evaluation of the venous anatomy around the gastro-esophageal junction in patients with portal hypertension. Hepatogastroenterology 1996; 43: $1250-1255$

[78] Lee YT, Chan FKL, Ching JYL et al. Diagnosis of Gastroesophageal Varices and Portal Collateral Venous Abnormalities by Endosonography in Cirrhotic Patients. Endoscopy 2002; 34: 391 - 8

[79] McKiernan PJ, Sharif K, Gupte GL. The role of endoscopic ultrasound for evaluating portal hypertension in children being assessed for intestinal transplantation. Transplantation 2008; 86: 1470-1473

[80] Konishi Y, Nakamura T, Kida H et al. Catheter US probe EUS evaluation of gastric cardia and perigastric vascular structures to predict esophageal variceal recurrence. Gastrointest Endosc 2002; 55: 197 203

[81] Miller LS, Schiano TD, Adrain A et al. Comparison of high-resolution endoluminal sonography to video endoscopy in the detection and evaluation of esophageal varices. Hepatology 1996; 24: $552-555$

[82] Burtin P, Calès P, Oberti F et al. Endoscopic ultrasonographic signs of portal hypertension in cirrhosis. Gastrointest Endosc 1996; 44: $257-261$

[83] Lo GH, Lai KH, Cheng JS et al. Prevalence of paraesophageal varices and gastric varices in patients achieving variceal obliteration by banding ligation and by injection sclerotherapy. Gastrointest Endosc 1999; 49: $428-436$

[84] Pontes JM, Leitão MC, Portela FA et al. Endoscopic ultrasonography in the treatment of oesophageal varices by endoscopic sclerotherapy and band ligation: do we need it? Eur ] Gastroenterol Hepatol 1995; 7: $41-46$

[85] Sgouros SN, Bergele C, Avgerinos A. Endoscopic ultrasonography in the diagnosis and management of portal hypertension. Where are we next? Dig Liver Dis 2006; 38: 289-295

[86] Curcio G. Case of obscure-overt gastrointestinal bleeding after pediatric liver transplantation explained by endoscopic ultrasound. World J Gastrointest Endosc 2012; 4: 571

[87] Rana S, Bhasin D, Chaudhary V et al. Clinical, endoscopic and endoscopic ultrasound features of duodenal varices: A report of 10 cases. Endosc Ultrasound 2014; 3: 54

[88] Rana SS. Sample Organization. Communication of duodenal varix with pericholedochal venous plexus demonstrated by endoscopic ultrasound in a patient of portal biliopathy. Endosopic Ultrasound 2012; $1: 165$

[89] Rana SS, Bhasin DK, Singh K. Duodenal varix diagnosed by endoscopic ultrasound. Clin Gastroenterol Hepatol 2010; 8: A24 
[90] Sharma M, Mohan P, Rameshbabu CS et al. Identification of perforators in patients with duodenal varices by endoscopic ultrasound-a case series [with video]. J Clin Exp Hepatol 2012; 2: 229-237

[91] Liu JB, Miller LS, Feld RI et al. Gastric and esophageal varices: $20-\mathrm{MHz}$ transnasal endoluminal US. Radiology 1993; 187: 363-366

[92] Nishizono M, Haraguchi Y, Eto T et al. Endoscopic ultrasonography using a $15 / 20 \mathrm{MHz}$ probe in a direct contact technique: evaluation and application in esophageal and gastric varices. Fukuoka Igaku Zasshi Hukuoka Acta Medica 1994; 85: 251 - 255

[93] Suzuki T, Matsutani S, Umebara K et al. EUS changes predictive for recurrence of esophageal varices in patients treated by combined endoscopic ligation and sclerotherapy. Gastrointest Endosc 2000; 52: $611-617$

[94] Nakamura H, Endo M, Shimojuu K et al. Esophageal varices evaluated by endoscopic ultrasonography: observation of collateral circulation during non-shunting operations. Surg Endosc 1990; 4: 69-74; discussion 75

[95] Caletti GC, Brocchi E, Ferrari A et al. Value of endoscopic ultrasonography in the management of portal hypertension. Endoscopy 1992; 24: $342-346$

[96] Avunduk C, Hampf F. Endoscopic ultrasound in the diagnosis of watermelon stomach. J Clin Gastroenterol 1996; 22: 104-106

[97] Parente F, Petrillo M, Vago L et al. The watermelon stomach: clinical, endoscopic, endosonographic, and therapeutic aspects in three cases. Endoscopy 1995; 27: 203-206

[98] Chen TK, Wu CH, Lee CL et al. Endoscopic ultrasonography in the differential diagnosis of giant gastric folds. J Formos Med Assoc Taiwan Yi Zhi 1999; 98: 261-264

[99] Wong RCK, Farooq FT, Chak A. Endoscopic Doppler US probe for the diagnosis of gastric varices (with videos). Gastrointest Endosc 2007; 65: $491-496$

[100] Giday SA, Clarke JO, Buscaglia JM et al. EUS-guided portal vein catheterization: a promising novel approach for portal angiography and portal vein pressure measurements. Gastrointest Endosc 2008; 67: $338-342$

[101] Lai L, Poneros J, Santilli j et al. EUS-guided portal vein catheterization and pressure measurement in an animal model: a pilot study of feasibility. Gastrointest Endosc 2004; 59: $280-283$

[102] Giday SA, Ko C-W, Clarke JO et al. EUS-guided portal vein carbon dioxide angiography: a pilot study in a porcine model. Gastrointest Endosc 2007; 66: 814-819

[103] Schulman AR, Thompson CC, Ryou M. EUS-guided portal pressure measurement using a digital pressure wire with real-time remote display: a novel, minimally invasive technique for direct measurement in an animal model. Gastrointest Endosc 2016; 83: 817-820

[104] Schulman AR, Thompson CC, Ryou M. Endoscopic ultrasound-guided direct portal pressure measurement using a digital pressure wire with real-time remote display: a survival study. J Laparoendosc Adv Surg Tech A 2017; 27: 1051 - 1054

[105] Magno P, Ko C-W, Buscaglia JM et al. EUS-guided angiography: a novel approach to diagnostic and therapeutic interventions in the vascular system. Gastrointest Endosc 2007; 66: 587-591

[106] Fujii-Lau L, Leise M, Kamath P et al. Endoscopic ultrasound-guided portal-systemic pressure gradient measurement. Endoscopy 2014; 46: E654-E656

[107] Huang JY, Samarasena JB, Tsujino T et al. EUS-guided portal pressure gradient measurement with a simple novel device: a human pilot study. Gastrointest Endosc 2017; 85: 996 - 1001

[108] Jackson FW, Adrain AL, Black M et al. Calculation of esophageal variceal wall tension by direct sonographic and manometric measurements. Gastrointest Endosc 1999; 50: 247-251
[109] Miller ES, Kim JK, Gandehok J et al. A new device for measuring esophageal variceal pressure. Gastrointest Endosc 2002; 56: 284 291

[110] Miller LS, Dai Q, Thomas A et al. A new ultrasound-guided esophageal variceal pressure-measuring device. Am J Gastroenterol 2004; 99: $1267-1273$

[111] Pontes JM, Leitão MC, Portela F et al. Endosonographic Dopplerguided manometry of esophageal varices: experimental validation and clinical feasibility. Endoscopy 2002; 34: 966 -972

[112] Schiano TD, Adrain AL, Vega KJ et al. High-resolution endoluminal sonography assessment of the hematocystic spots of esophageal varices. Gastrointest Endosc 1999; 49: 424-427

[113] Miller L, Banson FL, Bazir K et al. Risk of esophageal variceal bleeding based on endoscopic ultrasound evaluation of the sum of esophageal variceal cross-sectional surface area. Am J Gastroenterol 2003; 98: $454-459$

[114] Sato T, Yamazaki K, Toyota J et al. Observation of Gastric Variceal Flow characteristics by endoscopic ultrasonography using color Doppler. Am J Gastroenterol 2008; 103: 575-580

[115] Irisawa A, Saito A, Obara K et al. Endoscopic recurrence of esophageal varices is associated with the specific EUS abnormalities: Severe periesophageal collateral veins and large perforating veins. Gastrointest Endosc 2001; 53: 77 - 84

[116] Faigel DO, Rosen HR, Sasaki A et al. EUS in cirrhotic patients with and without prior variceal hemorrhage in comparison with noncirrhotic control subjects. Gastrointest Endosc 2000; 52: 455-462

[117] Irisawa A, Obara K, Sato Y et al. EUS analysis of collateral veins inside and outside the esophageal wall in portal hypertension. Gastrointest Endosc 1999; 50: 374-380

[118] Men C, Zhang G. Endoscopic ultrasonography predicts early esophageal variceal bleeding in liver cirrhosis: A case report. Medicine (Baltimore) 2017; 96: e6749

[119] Kume K, Yamasaki M, Watanabe T et al. Mild collateral varices and a fundic plexus without perforating veins on EUS predict endoscopic non-recurrence of esophageal varices after EVL. Hepatogastroenterology 2011; 58: 798-801

[120] Masalaite L, Valantinas ], Stanaitis ]. The role of collateral veins detected by endosonography in predicting the recurrence of esophageal varices after endoscopic treatment: a systematic review. Hepatol Int 2014; 8: 339-351

[121] Seno $\mathrm{H}$, Konishi $\mathrm{Y}$, Wada $\mathrm{M}$ et al. Improvement of collateral vessels in the vicinity of gastric cardia after endoscopic variceal ligation therapy for esophageal varices. Clin Gastroenterol Hepatol Off Clin Pract J Am Gastroenterol Assoc 2004; 2: 400-404

[122] Sato T, Yamazaki K, Toyota J et al. Perforating veins in recurrent esophageal varices evaluated by endoscopic color Doppler ultrasonography with a galactose-based contrast agent. J Gastroenterol 2004; 39: $422-428$

[123] Sato T, Yamazaki K, Toyota J et al. Endoscopic ultrasonographic evaluation of hemodynamics related to variceal relapse in esophageal variceal patients. Hepatol Res 2009; 39: 126-133

[124] Masalaite L, Valantinas J, Stanaitis J. Endoscopic ultrasound findings predict the recurrence of esophageal varices after endoscopic band ligation: a prospective cohort study. Scand J Gastroenterol 2015; 50: $1322-1330$

[125] Leung VK, Sung J], Ahuja AT et al. Large paraesophageal varices on endosonography predict recurrence of esophageal varices and rebleeding. Gastroenterology 1997; 112: 1811 - 1816

[126] Irisawa A, Obara K, Bhutani MS et al. Role of para-esophageal collateral veins in patients with portal hypertension based on the results of endoscopic ultrasonography and liver scintigraphy analysis. J Gastroenterol Hepatol 2003; 18: 309-314 
[127] Carneiro FOAA, Retes FA, Matuguma SE et al. Role of EUS evaluation after endoscopic eradication of esophageal varices with band ligation. Gastrointest Endosc 2016; 84: 400 - 407

[128] Dhiman RK, Choudhuri G, Saraswat VA et al. Role of paraoesophageal collaterals and perforating veins on outcome of endoscopic sclerotherapy for oesophageal varices: an endosonographic study. Gut 1996; 38: $759-764$

[129] Elsamman MK, Fujiwara Y, Kameda $\mathrm{N}$ et al. Predictive factors of worsening of esophageal varices after balloon-occluded retrograde transvenous obliteration in patients with gastric varices. Am J Gastroenterol 2009; 104: 2214-2221

[130] Kuramochi A, Imazu H, Kakutani H et al. Color Doppler endoscopic ultrasonography in identifying groups at a high-risk of recurrence of esophageal varices after endoscopic treatment. J Gastroenterol 2007; 42: 219-224

[131] Hino S, Kakutani H, Ikeda K et al. Hemodynamic analysis of esophageal varices using color Doppler endoscopic ultrasonography to predict recurrence after endoscopic treatment. Endoscopy 2001; 33: $869-872$

[132] Liao W-C, Chen P-H, Hou M-C et al. Endoscopic ultrasonography assessment of para-esophageal varices predicts efficacy of propranolol in preventing recurrence of esophageal varices. J Gastroenterol 2015; 50: $342-349$

[133] Escorsell A, Bordas JM, Feu F et al. Endoscopic assessment of variceal volume and wall tension in cirrhotic patients: effects of pharmacological therapy. Gastroenterology 1997; 113: 1640-1646

[134] Lee YT, Sung J], Yung MY et al. Use of color Doppler EUS in assessing azygos blood flow for patients with portal hypertension. Gastrointest Endosc 1999; 50: 47 - 52

[135] Nishida H, Giostra E, Spahr L et al. Validation of color Doppler EUS for azygos blood flow measurement in patients with cirrhosis: Application to the acute hemodynamic effects of somatostatin, octreotide, or placebo. Gastrointest Endosc 2001; 54: 24-30

[136] Hansen EF, Bendtsen F, Brinc K. Endoscopic Doppler ultrasound for measurement of azygos blood flow: validation against thermodilution and assessment of pharmacological effects of terlipressin in portal hypertension. scand $\mathrm{j}$ gastroenterol 2001; 36: 318-325

[137] McDermott S, Gervais D. Radiofrequency ablation of liver tumors. Semin Interv Radiol 2013; 30: 049-055

[138] Varadarajulu S, Jhala NC, Drelichman ER. EUS-guided radiofrequency ablation with a prototype electrode array system in an animal model (with video). Gastrointest Endosc 2009; 70: 372 - 376

[139] Yoon WJ, Daglilar ES, Kamionek M et al. Evaluation of radiofrequency ablation using a 1-Fr wire electrode in porcine pancreas, liver, gallbladder, spleen, kidney, stomach, and lymph nodes: A pilot study: RFA of abdominal organs. Dig Endosc 2016; 28: 465-468

[140] Rustagi T, Gleeson FC, Abu Dayyeh BK et al. Evaluation of Effects of Radiofrequency Ablation of Ex vivo Liver Using the 1-Fr Wire Electrode. J Clin Gastroenterol 2018; 52: 168-171

[141] Hines-Peralta A, Hollander CY, Solazzo S et al. Hybrid radiofrequency and cryoablation device: preliminary results in an animal model. J Vasc Interv Radiol 2004; 15: 1111 - 1120

[142] Carrara S, Arcidiacono P, Albarello L et al. Endoscopic ultrasoundguided application of a new internally gas-cooled radiofrequency ablation probe in the liver and spleen of an animal model: a preliminary study. Endoscopy 2008; 40: 759-763

[143] Di Matteo F, Grasso R, Pacella CM et al. EUS-guided Nd:YAG laser ablation of a hepatocellular carcinoma in the caudate lobe. Gastrointest Endosc 2011; 73: 632 - 636

[144] Jiang T, Tian G, Bao $\mathrm{H}$ et al. EUS dating with laser ablation against the caudate lobe or left liver tumors: a win-win proposition? Cancer Biol Ther 2018; 19: $145-152$
[145] Pioche M, Lafon C, Constanciel E et al. High-intensity focused ultrasound liver destruction through the gastric wall under endoscopic ultrasound control: first experience in living pigs. Endoscopy 2012; 44: E376-E377

[146] Li T, Khokhlova T, Maloney E et al. Endoscopic high-intensity focused US: technical aspects and studies in an in vivo porcine model (with video). Gastrointest Endosc 2015; 81: 1243 - 1250

[147] Nakaji S, Hirata N, Mikata R et al. Clinical outcomes of endoscopic ultrasound-guided ethanol injection for hepatocellular carcinoma in the caudate lobe. Endosc Int Open 2016; 04: E111-E115

[148] DiMaio CJ. Sp616 EUS-guided ethanol ablation for management of metastatic hepatocellular carcinoma. Gastrointest Endosc 2013; 77: AB115

[149] Nakaji S, Hirata N, Iwaki K et al. Endoscopic ultrasound (EUS)-guided ethanol injection for hepatocellular carcinoma difficult to treat with percutaneous local treatment. Endoscopy 2012; 44: E380 - E380

[150] Jiang T, Deng Z, Tian G et al. Efficacy and safety of endoscopic ultrasonography-guided interventional treatment for refractory malignant left-sided liver tumors: a case series of 26 patients. Sci Rep 2015; 6: 36098

[151] Hu Y-H, Tuo X-P, jin Z-D et al. Endoscopic ultrasound (EUS)-guided ethanol injection in hepatic metastatic carcinoma: a case report. Endoscopy 2010; 42: E256-E257

[152] Barclay RL, Perez-Miranda M, Giovannini M. EUS-guided treatment of a solid hepatic metastasis. Gastrointest Endosc 2002; 55: 266 270

[153] Faigel D, Lake D, Landreth T et al. Endoscopic ultrasonographyguided portal injection chemotherapy for hepatic metastases. Endosc Ultrasound 2014; 3: S1

[154] Choi J-H, Seo D-W, Park DH et al. Fiducial placement for stereotactic body radiation therapy under only endoscopic ultrasonography guidance in pancreatic and hepatic malignancy: practical feasibility and safety. Gut Liver 2014; 8: 88-93

[155] Dhadham G, Hoffe S, Harris C et al. Endoscopic ultrasound-guided fiducial marker placement for image-guided radiation therapy without fluoroscopy: safety and technical feasibility. Endosc Int Open 2016; 04: E378-E382

[156] Hemming AW, Reed Al, Howard R] et al. Preoperative portal vein embolization for extended hepatectomy. Ann Surg 2003; 237: 686693

[157] Liu H, Fu Y. Portal vein embolization before major hepatectomy. World J Gastroenterol 2005; 11: 2051 - 2054

[158] Matthes K, Sahani D, Holalkere NS et al. Feasibility of endoscopic ultrasound-guided portal vein embolization with Enteryx. Acta Gastro-Enterol Belg 2005; 68: 412-415

[159] Lee S, Seo D-W, Paik WH et al. Ethanol lavage of huge hepatic cysts by using EUS guidance and a percutaneous approach. Gastrointest Endosc 2014; 80: 1014-1021

[160] Shi G, Sun S, Li H et al. A case of a giant cyst in the left lobe of the liver successfully treated with endoscopic ultrasound-guided fine needle aspiration (with video). Endosc Ultrasound 2017; 6: 343 346

[161] Cai Y-L, Xiong X-Z, Lu J et al. Percutaneous needle aspiration versus catheter drainage in the management of liver abscess: a systematic review and meta-analysis. HPB 2015; 17: 195-201

[162] Bertel CK, van Heerden JA, Sheedy PF. Treatment of pyogenic hepatic abscesses. Surgical vs percutaneous drainage. Arch Surg Chic III 1960 1986; 121: $554-558$

[163] Seewald S, Imazu H, Omar S et al. EUS-guided drainage of hepatic abscess. Gastrointest Endosc 2005; 61: $495-498$

[164] Ang T, Seewald S, Teo E et al. EUS-guided drainage of ruptured liver abscess. Endoscopy 2009; 41: E21-E22 
[165] Noh SH, Park DH, Kim YR et al. EUS-guided drainage of hepatic abscesses not accessible to percutaneous drainage (with videos). Gastrointest Endosc 2010; 71: 1314-1319

[166] Itoi T, Ang TL, Seewald S et al. Endoscopic ultrasonography-guided drainage for tuberculous liver abscess drainage: EUS-guided liver abscess drainage. Dig Endosc 2011; 23: 158-161

[167] Keohane J, Dimaio CJ, Schattner MA et al. EUS-guided transgastric drainage of caudate lobe liver abscesses. J Interv Gastroenterol 2011; $1: 139-141$

[168] Medrado B, Carneiro F, Vilaça T et al. Endoscopic ultrasound-guided drainage of giant liver abscess associated with transgastric migration of a self-expandable metallic stent. Endoscopy 2013; 45: E331 E332

[169] Alcaide N, Vargas-Garcia AL, de la Serna-Higuera C et al. EUS-guided drainage of liver abscess by using a lumen-apposing metal stent (with video). Gastrointest Endosc 2013; 78: 941 - 942

[170] Kawakami H, Kawakubo K, Kuwatani M et al. Endoscopic ultrasonography-guided liver abscess drainage using a dedicated, wide, fully covered self-expandable metallic stent with flared-ends. Endoscopy 2014; 46: E982-E983

[171] Tonozuka R, Itoi T, Tsuchiya T et al. EUS-guided drainage of hepatic abscess and infected biloma using short and long metal stents (with videos). Gastrointest Endosc 2015; 81: 1463 -1469

[172] Ogura T, Masuda D, Saori O et al. Clinical outcome of endoscopic ultrasound-guided liver abscess drainage using self-expandable covered metallic stent (with video). Dig Dis Sci 2016; 61: 303-308

[173] Koizumi K, Masuda S, Uojima H et al. Endoscopic ultrasound-guided drainage of an amoebic liver abscess extending into the hepatic subcapsular space. Clin J Gastroenterol 2015; 8: 232-235

[174] Kumta NA, Torres-Ruiz F, Reinoso PJ et al. Endoscopic management of hepatic abscess after EUS-guided hepaticogastrostomy. Gastrointest Endosc 2016; 84: 1054 - 1055

[175] Ogura T, Takagi W, Onda S et al. Endoscopic ultrasound-guided drainage of a right liver abscess with a self-expandable metallic stent. Endoscopy 2015; 47: E397 - E398

[176] Taguchi H, Tamai T, Numata M et al. Endoscopic ultrasonographyguided transmural drainage of an infected hepatic cyst due to Edwardsiella tarda: a case report. Clin J Gastroenterol 2014; 7: 422 428

[177] Kodama R, Saegusa H, Ushimaru H et al. Endoscopic ultrasonography-guided drainage of infected intracystic papillary adenocarcinoma of the liver. Clin J Gastroenterol 2015; 8: 335-339

[178] Nagamine N, Ueno N, Tomiyama T et al. A pilot study on modified endoscopic variceal ligation using endoscopic ultrasonography with color Doppler function. Am J Gastroenterol 1998; 93: 150-155

[179] Andrade de Paulo G, Ardengh JC, Nakao FS et al. Treatment of esophageal varices: a randomized controlled trial comparing endoscopic sclerotherapy and EUS-guided sclerotherapy of esophageal collateral veins. Gastrointest Endosc 2006; 63: 396-402

[180] Lahoti S, Catalano MF, Alcocer E et al. Obliteration of esophageal varices using EUS-guided sclerotherapy with color Doppler. Gastrointest Endosc 2000; 51: 331 - 333

[181] Kassem MA, Salama AZ, Zakaria SM et al. endoscopic ultrasonographic study of the azygos vein before and after endoscopic obliteration of esophagogastric varices by injection sclerotherapy. Endoscopy 2000; 32: 630-634

[182] Romero-Castro R, Ellrichmann M, Ortiz-Moyano C et al. EUS-guided coil versus cyanoacrylate therapy for the treatment of gastric varices: a multicenter study (with videos). Gastrointest Endosc 2013; 78: $711-721$

[183] Binmoeller KF, Weilert F, Shah JN et al. EUS-guided transesophageal treatment of gastric fundal varices with combined coiling and cya- noacrylate glue injection (with videos). Gastrointest Endosc 2011; 74: $1019-1025$

[184] Romero-Castro R, Pellicer-Bautista F], Jimenez-Saenz M et al. EUSguided injection of cyanoacrylate in perforating feeding veins in gastric varices: results in 5 cases. Gastrointest Endosc 2007; 66: $402-407$

[185] Iwase H, Suga S, Morise K et al. Color Doppler endoscopic ultrasonography for the evaluation of gastric varices and endoscopic obliteration with cyanoacrylate glue. Gastrointest Endosc 1995; 41: $150-154$

[186] Lee YT, Chan FKL, Ng EKW et al. EUS-guided injection of cyanoacrylate for bleeding gastric varices. Gastrointest Endosc 2000; 52: $168-174$

[187] Bhat YM, Weilert F, Fredrick RT et al. EUS-guided treatment of gastric fundal varices with combined injection of coils and cyanoacrylate glue: a large U. S. experience over 6 years (with video). Gastrointest Endosc 2016; 83: 1164-1172

[188] Tang RS, Teoh AY, Lau JY. EUS-guided cyanoacrylate injection for treatment of endoscopically obscured bleeding gastric varices. Gastrointest Endosc 2016; 83: $1032-1023$

[189] Storm AC, Kumbhari V, Saxena P et al. EUS-guided angiotherapy. Gastrointest Endosc 2014; 80: $164-165$

[190] Gubler C, Bauerfeind P. Safe and successful endoscopic initial treatment and long-term eradication of gastric varices by endoscopic ultrasound-guided Histoacryl ( $N$-butyl-2-cyanoacrylate) injection. Scand J Gastroenterol 2014; 49: 1136 - 1142

[191] Gonzalez J-M, Giacino C, Pioche M et al. Endoscopic ultrasoundguided vascular therapy: is it safe and effective? Endoscopy 2012; 44: $539-542$

[192] Rana SS, Bhasin DK, Rao C et al. Endoscopic ultrasound-guided treatment of bleeding duodenal varix. Indian J Gastroenterol 2011; 30: $280-281$

[193] Liao S-C, Yang S-S, Ko C-W et al. A miniature ultrasound probe is useful in reducing rebleeding after endoscopic cyanoacrylate injection for hemorrhagic gastric varices. Scand J Gastroenterol 2013; 48: $1347-1353$

[194] Romero-Castro R, Pellicer-Bautista F, Giovannini M et al. Endoscopic ultrasound (EUS)-guided coil embolization therapy in gastric varices. Endoscopy 2010; 42: E35 - E36

[195] Fujii-Lau LL, Law R, Wong Kee Song LM et al. Endoscopic ultrasound (EUS)-guided coil injection therapy of esophagogastric and ectopic varices. Surg Endosc 2016; 30: 1396 - 1404

[196] Levy MJ, Wong Kee Song LM et al. EUS-guided coil embolization for refractory ectopic variceal bleeding (with videos). Gastrointest Endosc 2008; 67: $572-574$

[197] Kinzel ], Pichetshote N, Dredar S et al. Bleeding from a duodena varix: a unique case of variceal hemostasis achieved using EUSguided placement of an embolization coil and cyanoacrylate. J Clin Gastroenterol 2014; 48: 362 - 364

[198] Krystallis C, McAvoy NC, Wilson J et al. EUS-assisted thrombin injection for ectopic bleeding varices-a case report and review of the literature. QJM 2012; 105: 355-358

[199] Buscaglia JM, Dray X, Shin EJ et al. A new alternative for a transjugular intrahepatic portosystemic shunt: EUS-guided creation of an intrahepatic portosystemic shunt (with video). Gastrointest Endosc 2009; 69: $941-947$

[200] Binmoeller KF, Shah JN. Sa1428 EUS-guided transgastric intrahepatic portosystemic shunt using the Axios stent. Gastrointest Endosc 2011; 73: AB167

[201] Schulman AR, Ryou M, Aihara $\mathrm{H}$ et al. EUS-guided intrahepatic portosystemic shunt with direct portal pressure measurements: a novel alternative to transjugular intrahepatic portosystemic shunting. Gastrointest Endosc 2017; 85: 243 - 247 